\title{
Observed Cardiac Device Type
}

National Cancer Institute

\section{Source}

National Cancer Institute. Observed Cardiac Device Type. NCI Thesaurus. Code C139049.

A description of the type of cardiac device that is found in a subject. 